\title{
Oligonucleotide Studies
}

\section{OPTICAL ROTATORY DISPERSION OF FIVE HOMODINUCLEOTIDES}

\author{
BY YASUO INOUE AND KIMIHIKO SATOH \\ Department of Chemistry, Tohoku University, Sendai, Japan
}

(Received 28 January 1969)

\begin{abstract}
1. The optical rotatory dispersion (ORD) of five homodinucleotides, $\operatorname{ApAp}\left(3^{\prime}\right)$, $\operatorname{CpCp}\left(3^{\prime}\right), \operatorname{GpGp}\left(3^{\prime}\right), \operatorname{IpIp}\left(3^{\prime}\right)$ and $\mathrm{UpUp}\left(3^{\prime}\right)$ (where A, C, G, I and U represent adenosine, cytidine, guanosine, inosine and uridine respectively, and $p$ to the left of a nucleoside symbol indicates a $5^{\prime}$-phosphate and to the right it indicates a $3^{\prime}$-phosphate), were measured as a function of $\mathrm{pH}$, ionic strength and $\mathrm{Mg}^{2+}$ concentration. 2. The ORD titrations of $\operatorname{ApAp}\left(3^{\prime}\right)$ and $\operatorname{CpCp}\left(3^{\prime}\right)$, which were made by measuring the ORD curves at closely spaced $\mathrm{pH}$ intervals, exhibit a maximum at approx. $\mathrm{pH} 5 \cdot 0$ and $5 \cdot 7$ for $\mathrm{ApAp}\left(3^{\prime}\right)$ and $\mathrm{CpCp}\left(3^{\prime}\right)$ respectively in the profile of the magnitude of the first Cotton effect versus $\mathrm{pH}$. The results indicate that the conformational rigidity of these dinucleotides depends on the ionization state of a $3^{\prime}$-terminal phosphate group. 3. ApAp $\left(3^{\prime}\right)$ was shown to exist as an approximately $1: 1$ equilibrium mixture of the two major ionic species represented by $\mathbf{A p}_{(-1)} \mathbf{A p}_{(-1)}$ and $\mathrm{Ap}_{(-1)} \mathrm{Ap}_{(-2)}$ at $\mathrm{pH} 6 \cdot 16$, whereas at $\mathrm{pH} 7 \cdot 5$ it exists exclusively as a form of $\operatorname{Ap}_{(-1)} A_{(-2)}$. 4. To ascertain the effects of the presence of a terminal phosphate group and of the ionization of the secondary phosphate on the conformation of adenylate dimer, we measured the ORD of ApA, $\operatorname{ApAp}\left(3^{\prime}\right) \mathrm{CH}_{3}$ and $\operatorname{ApAp}\left(2^{\prime}\right)$. The rotatory power of the first Cotton effect in the above series of dinucleotides decreased at $20^{\circ}$ in the order $\operatorname{ApA}>\operatorname{ApAp}\left(3^{\prime}\right) \mathrm{CH}_{3} \approx \operatorname{ApAp}\left(3^{\prime}\right)_{(-1)}>\operatorname{ApAp}\left(2^{\prime}\right)$ at $\mathrm{pH} 7>\operatorname{ApAp}\left(3^{\prime}\right)$ at $\mathrm{pH} 7$. 5. The $\mathrm{pH}$-rotation profiles were also obtained for $\operatorname{ApAp}\left(2^{\prime}\right), \mathrm{CpCp}\left(2^{\prime}\right)$ and $\mathrm{UpUp}\left(3^{\prime}\right)$, but no corresponding maximum was observed. Although simple nearest-neighbour calculations based on the ORD data of $\operatorname{IpIp}\left(3^{\prime}\right)$ and $5^{\prime}$-IMP account for the observed ORD spectrum of polyinosinic acid at low salt concentration, there were large discrepancies between calculated and experimental results of the polyguanylic acid ORD even at low ionic strength. 6. The extent to which the amplitude of the Cotton effects of $\operatorname{IpIp}\left(3^{\prime}\right)$ increases with salt concentration, especially by the addition of $\mathrm{Mg}^{2+}$, was much greater than that observed for $\operatorname{ApAp}\left(3^{\prime}\right)$. The implication of such salt effects on the ORD is considered.
\end{abstract}

Synthetic polyribonucleotides and oligonucleotides have been commonly used as models for naturally occurring nucleic acids (Fasman, Lindblow \& Grossman, 1964; Holcomb \& Tinoco, 1965; Van Holde, Brahms \& Michelson, 1965 ; Cantor, Jaskunas \& Tinoco, 1966; Brahms, Michelson \& Van Holde, 1966 ; Leng \& Felsenfeld, 1966 ; Vournakis, Scheraga, Rushizky \& Sober, 1966; Poland, Vournakis \& Scheraga, 1966; Simpkins \& Richards, 1967a; Jaskunas, Cantor \& Tinoco, 1968). Of these models, dinucleoside phosphates are the simplest one to provide much useful information about sequencedependent optical properties (Warshaw \& Tinoco, 1965, 1966; Cantor \& Tinoco, 1965, 1967; Bush \& Tinoco, 1967; Simpkins \& Richards, 1967b). With the aim of increasing our knowledge of the chemistry of oligoribonucleotides, we have also been under- taking their preparations and the ORD* and n.m.r. studies of simple oligoribonucleotides obtainable from either enzymic or non-enzymic hydrolysis of ribonucleic acids (Aoyagi \& Inoue, 1968a,b; Inoue, Aoyagi \& Nakanishi, 1967; Inoue \& Aoyagi, 1967, 1969; Irie, Egami \& Inoue, 1969). Dinucleotides thus obtained are differentiated from the corresponding dinucleoside phosphates by the presence of a terminal phosphate group in the former. Inoue et al. (1967) have reported that three

* Abbreviations: ORD, optical rotatory dispersion; in oligonucleotides $\mathrm{A}, \mathrm{C}, \mathrm{G}, \mathrm{I}$ and $\mathrm{U}$ represent adenosine, cytidine, guanosine, inosine and uridine respectively, and p to the left of a nucleoside symbol indicates a $5^{\prime}$-phosphate and to the right it indicates a $3^{\prime}$-phosphate (unless specified otherwise); polyG, polyguanylic acid; polyI, polyinosinic acid; polyU, polyuridylic acid. 
dinucleotides, ApGp, CpGp and UpGp, prepared from ribonuclease $T_{1}$ (EC 2.7.7.26) digestion of RNA, are substantially different in their ORD and hypochromicities from the corresponding dinucleoside phosphates. To further these observations and to understand the forces involved in making the optical properties of these two series of dimer units different, we have studied the effects of a terminal phosphate group of dinucleotides and the effects of the ionization of the secondary phosphate group on the ORD spectra. For simplicity, we decided to use homodinucleotides for these purposes.

It was observed that $\operatorname{ApAp}\left(3^{\prime}\right), \operatorname{ApAp}\left(3^{\prime}\right) \mathrm{CH}_{3}$ and ApA showed different ORD spectra at $\mathrm{pH} 7$, and, moreover, the rotation measured as $[\phi]_{283}-[\phi]_{260}$ of $\operatorname{ApAp}\left(3^{\prime}\right)$ at $20^{\circ}$ was found to increase by about $37 \%$ on changing the $\mathrm{pH}$ from 8 to $5 \cdot 1$. The present observed effect of the terminal phosphate group is ascribed to a change in the structure of hydration of the dinucleotide ions. We have also measured the ORD of $\operatorname{IpIp}\left(3^{\prime}\right)$ and GpGp$\left(3^{\prime}\right)$ at $25^{\circ}$, and the results suggest that at high concentrations of salt, e.g. magnesium chloride, IpIp seems to undergo aggregation. The ORD of polyI and polyG at a low salt concentration were calculated from the ORD curves of the corresponding dinucleotides and component monomers, and these calculations are compared with the reported experimental results for polyI and polyG.

\section{MATERIALS AND METHODS}

Preparation of dinucleotides. Pure dinucleotides used in this study were prepared by a partial hydrolysis of RNA in $0.2 \mathrm{M}-\mathrm{NaOH}$ followed by column-chromatographic separations with DEAE-Sephadex A-25 and Dowex l (X2) anionexchangers. The details of the preparation are reported elsewhere (Satoh \& Inoue, 1969). Dinucleoside phosphates, $\mathrm{ApA}$ and $\mathrm{CpC}$, were obtained from enzymic dephosphorylation of $\mathrm{ApAp}\left(2^{\prime}\right)$ or $\mathrm{ApAp}\left(3^{\prime}\right)$ and $\mathrm{CpCp}\left(2^{\prime}\right)$ with alkaline phosphatase (Sigma Chemical Co., St Louis, Mo., U.S.A.) at $36^{\circ}, \mathrm{pH}$ about 9 . Dinucleotides and the dephosphorylated products were desalted in a similar manner to that described by Aoyagi \& Inoue $(1968 b)$. $\operatorname{IpIp}\left(3^{\prime}\right)$ was prepared by deamination of $\operatorname{ApAp}\left(3^{\prime}\right)$ according to a modification of the method of Uchida \& Egami (1965); acetic acid (1.3 ml.) was added dropwise to the mixture of $\operatorname{ApAp}\left(3^{\prime}\right)(6 \mathrm{mg}$. of the diammonium salt $/ 0.5 \mathrm{ml}$. of water) and $\mathrm{NaNO}_{2}$ solution $\left(500 \mathrm{mg} . / 0.9 \mathrm{ml}\right.$. of water) under stirring for $12 \mathrm{hr}$. at $10-15^{\circ}$. The solution was then diluted to about $200 \mathrm{ml}$. and neutralized with alkali. The neutral solution was further diluted to 10 vol. with glass-distilled water and adsorbed on a small column of DEAE-Sephadex A-25 ( $\mathrm{HCO}_{3}-$ form). After the column had been washed with $0.02 \mathrm{M}-\mathrm{NH}_{4} \mathrm{HCO}_{3}$ (2l.), $\operatorname{IpIp}\left(3^{\prime}\right)$ was eluted with $1 \cdot 0 \mathrm{M}-\mathrm{NH}_{4} \mathrm{HCO}_{3}$. Water and the excess of salt were removed by freeze-drying.

Preparation of $A p A p\left(3^{\prime}\right) \mathrm{CH}_{3}$. Diammonium salt of ApAp(3') (3.4 mg.) was dissolved in $0.2-0.3 \mathrm{ml}$. of distilled water, and a total of $25 \cdot 6$ molar equivalents of ethereal diazomethane (1.59 ml. of $77 \mathrm{~mm}$ solution) was added to the dinucleotide solution. The concentration of ethereal diazomethane was determined by treatment with excess of benzoic acid and titration of the excess of acid with a standard solution of $\mathrm{NaOH}$. Diazomethane was consumed very rapidly in aqueous solution, and the reaction was followed with an autorecording spectropolarimeter by measuring changes in the rotatory-power ratio at 240 and $283 \mathrm{~nm}$. observed during the gradual addition of ethereal diazomethane. In the methylation reaction with diazomethane, the base part is believed to remain unchanged (Haines, Reese \& Todd, 1964). The reaction mixture was charged on a column $(1.0 \mathrm{~cm} . \times 91 \mathrm{~cm}$.) of DEAE-cellulose ( $\mathrm{Cl}-\mathrm{form})$, pre-equilibrated with tris buffer $(0.02 \mathrm{M}$-tris-chloride, pH 7.6). The methylated products were then eluted with a 21. linear gradient from 0 to $0 \cdot 1 \mathrm{M}-\mathrm{NaCl}$ at $\mathrm{pH} 7 \cdot 6$. The fraction volume was $4 \mathrm{ml}$. and flow rate $28 \mathrm{ml}$./ $\mathrm{hr}$. Under these conditions $\mathrm{ApAp}\left(2^{\prime}\right) \mathrm{CH}_{3}$ was eluted faster than $\mathrm{ApAp}\left(3^{\prime}\right) \mathrm{CH}_{3}$. The ApAp $\left(3^{\prime}\right) \mathrm{CH}_{3}$ fractions were combined and desalted. The ratio of $\mathrm{ApAp}\left(3^{\prime}\right) \mathrm{CH}_{3}$ to the migrated product $\mathrm{ApAp}\left(2^{\prime}\right) \mathrm{CH}_{3}$ was $79: 21$ and the yield of the 3 '-isomer was approx. $46 \%$. The position of the methyl phosphate group was determined with the aid of ribonuclease $\mathbf{T}_{\mathbf{2}}$ action. The migration of a $3^{\prime}$-terminal phosphate group to 2 '-terminus was also observed during the methylation of $3^{\prime}$-AMP with diazomethane (Schweizer, Broom, Ts'o \& Hollis, 1968).

$O R D$ measurements. Salt-free samples were dissolved in about $4 \mathrm{ml}$. of appropriate buffer solutions to give $\boldsymbol{E}_{\mathbf{2 6 0}}$ values of approx. 1.0. All buffers were prepared with glass-distilled water. Buffers used contained $0.02 \mathrm{M}$-trischloride (above pH 7.0), $0.02 \mathrm{M}-\mathrm{Na}_{2} \mathrm{HPO}_{4}-\mathrm{KH}_{2} \mathrm{PO}_{4}(\mathrm{pH} 5 \cdot 0-$ 7.0), 0.02 M-sodium acetate buffer $(\mathrm{pH} 3.0-6.0)$ and $\mathrm{HCl}$ (below $\mathrm{pH} 3 \cdot 0$ ). Ionic strength of the solution was adjusted by addition of dry $\mathrm{KCl}$ (or $\mathrm{NaCl}$ ) (analytical grade) to the sample solution. Exact extinction measurements were then made with a Hitachi Perkin-Elmer 139 spectrophotometer at $260 \mathrm{~nm}$. with buffer solution of the same components as reference. The $\mathrm{pH}$ measurements of the sample solutions were made with a Radiometer model TTT $1 \mathrm{~b}$ pHmeter after it had been calibrated with 0.05 M-potassium hydrogen phthalate and $0.05 \mathrm{M}$-sodium borate standard solutions. The molar concentration of each solution was calculated with the aid of hypochromicity measurements at $260 \mathrm{~nm}$. The hypochromicities were determined at $20^{\circ}$ at $\mathrm{pH} 7$ by alkaline hydrolysis of the samples by the method reported by Aoyagi \& Inoue (1968a). Hypochromicity data necessary for ORD calculations are the following values of $h(\%)$ at $260 \mathrm{~nm}$. : ApA, $9 \cdot 6 ; \operatorname{ApAp}\left(3^{\prime}\right), 9 \cdot 1 ; \operatorname{ApAp}\left(2^{\prime}\right), 10 \cdot 4$; $\mathrm{ApAp}\left(3^{\prime}\right) \mathrm{CH}_{3}, 9 \cdot 3 ; \mathrm{CpC}, 7 \cdot 8 ; \mathrm{CpCp}\left(3^{\prime}\right), 6 \cdot 4 ; \mathrm{UpUp}\left(3^{\prime}\right), 3 \cdot 5$; GpGp(3'), 8.4; IpIp $\left(3^{\prime}\right), 6 \cdot 0$.

ORD measurements were made on a Jasco model ORD/ UV-5 spectropolarimeter with a $1 \mathrm{~cm}$. thermostatically controlled cell. To ascertain the reproducibility, measurements were repeated at least twice for each sample. Net values of optical rotation were read at $2 \mathrm{~nm}$. intervals (but $1 \mathrm{~nm}$. intervals near extrema) after averaging of the 'noise' of ORD curves and blanks. Blanks were measured before and after the ORD measurement of each sample. Rotations were expressed in molar rotation per residue, $[\phi]$, defined as :

$$
[\phi]=\frac{[M]}{n}=\frac{100 \alpha \epsilon_{260}}{n E_{260}}
$$

where $n$ is the number of base residues in a molecule (for $X \mathrm{p} X$ and $X \mathrm{p} X \mathrm{p}, n=2),[M]$ the molecular rotation, $\alpha$ the observed rotations in degrees, and $E_{260}$ and $\epsilon_{260}$ are the 
extinction at $260 \mathrm{~nm}$. of a sample solution and molar extinction coefficient at the same wavelength respectively.

\section{RESULTS AND DISCUSSION}

Effect of the terminal phosphate group. The effect of the terminal phosphate group on molecular geometry of an oligonucleotide is not understood, although some observations have been reported (Nirenberg \& Leder, 1964; Lipsett, 1964) on the effect of the presence of a terminal phosphate group on the equilibrium position in intermolecular associations through hydrogen-bonding. In general, removal of the terminal phosphate from an oligonucleotide would facilitate such intermolecular interactions (Jaskunas et al. 1968).

Inoue et al. (1967) have reported preliminary results of our observations that three dinucleotides, ApGp, CpGp and UpGp, were substantially different in their ORD patterns from the corresponding dinucleoside phosphates, ApG, CpG and UpG. As a possible origin of these observations, we considered differences in base-ribose and base-phosphate interactions between a dinucleotide and its dinucleoside phosphate. However, it is generally accepted that the ORD of a nucleotide and nucleoside are not much different in the wavelength range 230-300nm. (Warshaw, Bush \& Tinoco, 1965; Yang, Samejima \& Sarkar, 1966), and, in fact, we have confirmed that the difference ORD defined as $[\phi]_{\text {ApAp (3') }}-2[\phi]_{3^{\prime} \cdot \text { AMP }}$ still significantly differs from the difference ORD, $[\phi]_{\mathrm{ApA}}-\left([\phi]_{3^{\prime}-\mathrm{AMP}}+[\phi]_{\text {adenosine }}\right)$ or $[\phi]_{\text {ApA }}-\left([\phi]_{\text {adenosine }}+[\phi]_{5^{\prime} \text {-AMP }}\right)$. This indicates the importance of the presence of a $3^{\prime}$-terminal phosphate group in contributing to the perturbation of base-base interactions in ApA. To understand this effect of the terminal phosphate, we have measured the ORD spectra of ApA, ApAp $\left(3^{\prime}\right)$, $\operatorname{ApAp}\left(3^{\prime}\right) \mathrm{CH}_{3}$ and $\operatorname{ApAp}\left(2^{\prime}\right)$ at $\mathrm{pH} 7$ and $I 0 \cdot 1$. The results are reproduced in Fig. 1. At this $\mathrm{pH}$ ApA, $\operatorname{ApAp}\left(3^{\prime}\right), \operatorname{ApAp}\left(3^{\prime}\right) \mathrm{CH}_{3}$ and $\operatorname{ApAp}\left(2^{\prime}\right)$ have the negative charges approx. $-1,-3,-2$ and -3 respectively. The presence of a $3^{\prime}$-phosphate on ApA decreases the amplitude of the first Cotton effect at $\mathrm{pH} 7.5$ at $20^{\circ}$ by about $45 \%$ of that for the dephosphorylated compound. A similar effect was also observed with $\mathrm{CpCp}\left(3^{\prime}\right)$ and $\mathrm{CpC}$. When the charge number of the terminal phosphate is decreased from -2 to -1 by the reaction of $\operatorname{ApAp}\left(3^{\prime}\right)$ with diazomethane to form $\operatorname{ApAp}\left(3^{\prime}\right) \mathrm{CH}_{3}$, the rotatory power measured as $[\phi]_{283}-[\phi]_{260}$ increases as much as $42 \%$, whereas the magnitude increases only $7.7 \%$ at $20^{\circ}$ on going from $\operatorname{ApAp}\left(3^{\prime}\right)$ $\mathrm{CH}_{3}$ to ApA. These changes in the rotatory power must be primarily due to the appearance of the electrostatic potential at the negatively charged site of the internucleotide phosphate group arising from the charged terminal phosphate group on substituting a $3^{\prime}$-hydroxyl (or 2'-hydroxyl) group with a phosphate. Another point is the change of the ratio of the molar rotations at the two wavelengths close to the peaks of the Cotton effects. The ratio of the molar rotation at $240 \mathrm{~nm}$. to that at $283 \mathrm{~nm}$. changes from 2.05 to 0.98 in going from $\operatorname{ApAp}\left(3^{\prime}\right)$ to ApA. The results are summarized in Table 1. Before discussion of the results, it is appropriate to present further evidence for the effect of the $3^{\prime}$-terminal phosphate charge on a

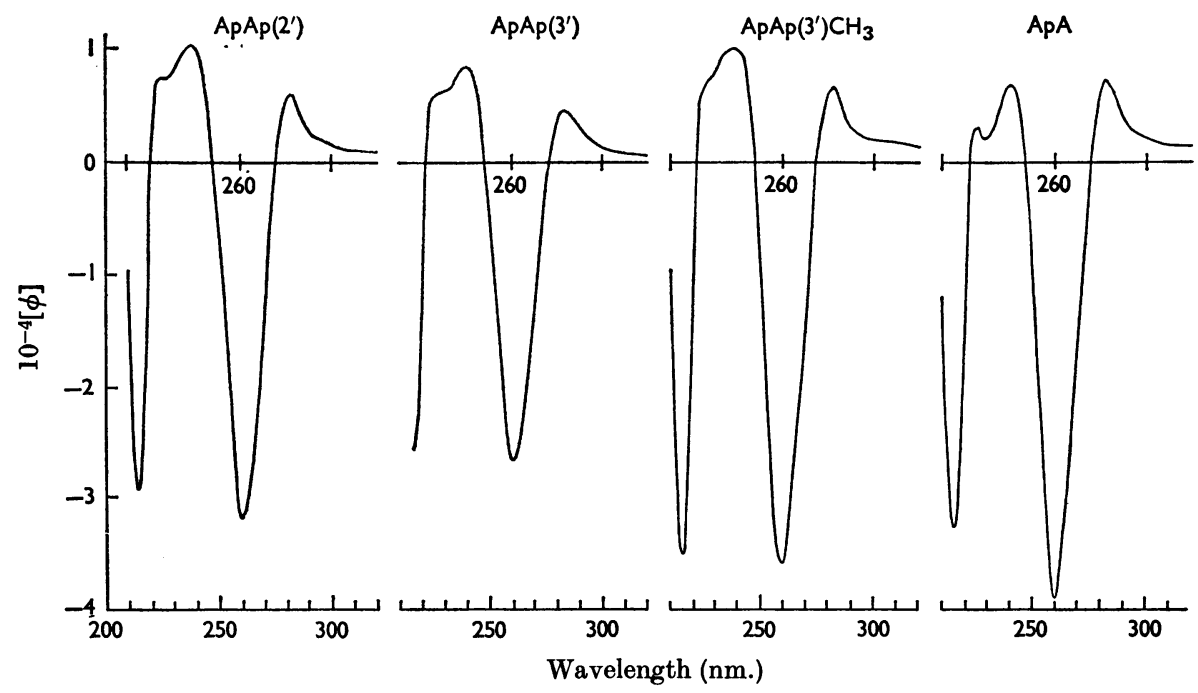

Fig. 1. ORD (in molar rotation/residue) of adenylate dimers at $\mathrm{pH} 7.0$ and $I 0.1$ at $20^{\circ}$. 
Table 1. Ratio of the molar rotation/residue at $240 \mathrm{~nm}$. to that at $283 \mathrm{~nm}$. at $I 0 \cdot 1$ at $20^{\circ}$

\begin{tabular}{|c|c|c|c|c|}
\hline Dimer & pH & {$[\phi]_{240}$} & {$[\phi]_{283}$} & {$[\phi]_{240} /[\phi]_{283}$} \\
\hline \multirow[t]{3}{*}{$\mathbf{A p A p}\left(\mathbf{3}^{\prime}\right)$} & $7 \cdot 34$ & 9080 & 4430 & 2.05 \\
\hline & $7 \cdot 0$ & 8430 & 4530 & $1 \cdot 86$ \\
\hline & $4 \cdot 88$ & 9560 & 6800 & $1 \cdot 41$ \\
\hline $\operatorname{ApAp}\left(3^{\prime}\right) \mathrm{CH}_{3}$ & $7 \cdot 03$ & 10100 & 6500 & 1.55 \\
\hline ApA & $7 \cdot 0$ & 6870 & 7000 & 0.98 \\
\hline $\operatorname{ApAp}\left(2^{\prime}\right)$ & $7 \cdot 0$ & 8670 & 4520 & 1.92 \\
\hline
\end{tabular}

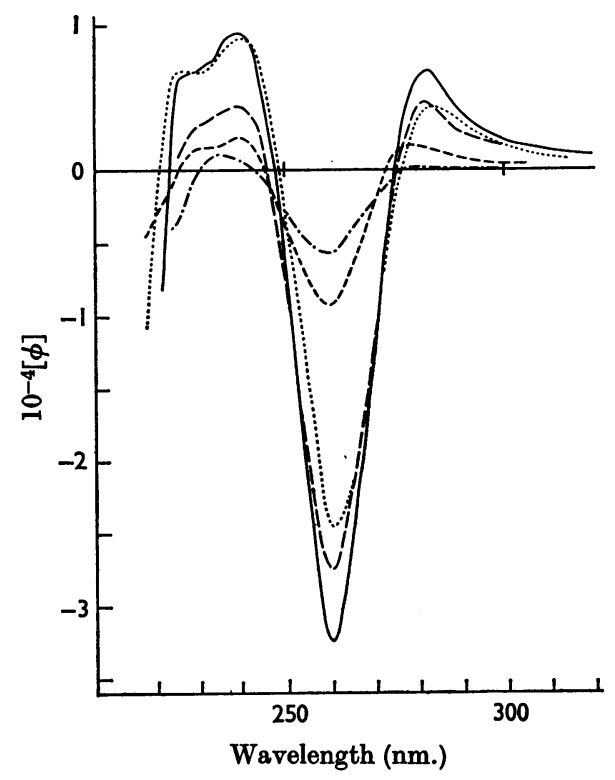

Fig. 2. $\mathrm{pH}$-dependence of the ORD of $\operatorname{ApAp}\left(3^{\prime}\right)$ at $I 0.1$ at $20^{\circ}$ : ......., pH 7.34; — ......., pH $2 \cdot 83 ; \cdot . \cdot-\cdot-, \mathrm{pH} 1 \cdot 88$.

dimer conformation, which comes from observations of changes in the ORD of various dinucleotides when titrated.

ORD titration properties of adenylate, cytidylate and uridylate dimers. Although no effect of $\mathrm{pH}$ in the range 4.9-8.9 on the ORD curve of $5^{\prime}$-AMP was observed (Schweizer et al. 1968), one would expect to be able to detect a pronounced effect of the ionization of the secondary phosphate on the ORD of adenylate dimer and certain other dinucleotides having a $3^{\prime}$-terminal phosphate. Potentiometric titration of $\operatorname{ApAp}\left(3^{\prime}\right)$ exhibits an acidic $\mathrm{p} K_{a}$ of approx. 6.16, which is responsible for the ionization equilibrium of the $3^{\prime}$-terminal secondary phosphate. The ORD spectra of $\mathrm{ApAp}\left(3^{\prime}\right)$ at several $\mathrm{pH}$ values are shown in Fig. 2. The magnitude of the first Cotton effect rises with decreasing $\mathrm{pH}$ from 7 to a maximum at $\mathrm{pH}$ about 5 , followed by a rather steep

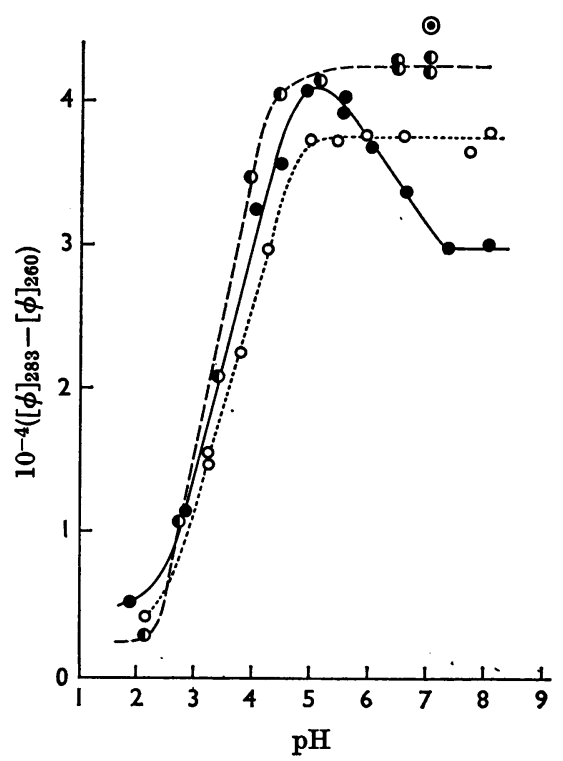

Fig. 3. pH-rotation profiles at $I 0.1$ at $20^{\circ}: 0, \operatorname{ApAp}\left(3^{\prime}\right)$; D, $\operatorname{ApAp}\left(3^{\prime}\right) \mathrm{CH}_{3} ;$ O, ApAp$\left(2^{\prime}\right) ; \odot$, ApA.

decrease until eventually the rotation of the fully protonated form of $A p A p\left(3^{\prime}\right)$ was observed. The plot of the amplitude, $[\phi]_{283}-[\phi]_{260}$ (this eliminates errors due to blank shifts between readings) against $\mathrm{pH}$ is shown for $\mathrm{ApAp}\left(3^{\prime}\right)$ together with those for $\operatorname{ApAp}\left(2^{\prime}\right)$ and $\mathrm{ApAp}\left(3^{\prime}\right) \mathrm{CH}_{3}$ in Fig. 3. As is clear from Fig. 3, the titrations of $\operatorname{ApAp}\left(3^{\prime}\right)$ in the $\mathrm{pH}$ range $8 \cdot 0-5 \cdot 0$ are apparently consistent with the continuous alteration of the conformation from $\operatorname{ApAp}\left(3^{\prime}\right)$ towards $\mathrm{ApAp}\left(3^{\prime}\right) \mathrm{CH}_{3}$. The consistent changes of the ratio of the rotatory power at 240 and $283 \mathrm{~nm}$. were also seen during the ORD titration of $\mathrm{ApAp}\left(3^{\prime}\right)$ at the $\mathrm{pH}$ range of the $\mathrm{p} K_{a}$ of the secondary phosphate. Representative data are included in Table 1. What we observed in the pH range 7.0-5.0 during the ORD titration of ApAp(3') can be approximated by the structural change resulting from an equilibrium:

$$
\mathrm{Ap}_{(-1)} \mathrm{Ap}_{(-1)}+\mathrm{H}_{2} \mathrm{O} \rightleftharpoons \mathrm{Ap}_{(-1)} \mathrm{Ap}_{(-2)}+\mathrm{H}_{3} \mathrm{O}^{+}
$$

However, because of the overlapping nature of the ionization constants involved in the possible prototropic scheme shown in Scheme 1 and uncertainty of exact values of microscopic equilibrium quotients, it is not, in practice, permissible to isolate the optical properties of the pure ionic form represented by $\mathrm{Ap}_{(-1)} \mathrm{Ap}_{(-1)}$. Nevertheless the $\mathrm{pH}$-rotation profile for ApAp $\left(3^{\prime}\right)$ in Fig. 3 strongly indicates that the rotatory power of $A p_{(-1)} A_{(-1)}$ is well approximated by that of $\operatorname{Ap}_{(-1)} \mathrm{Ap}_{(-1)}\left(3^{\prime}\right) \mathrm{CH}_{3}$. Assuming that the two bases in $\operatorname{ApAp}\left(3^{\prime}\right)$ in aqueous solutions are in 


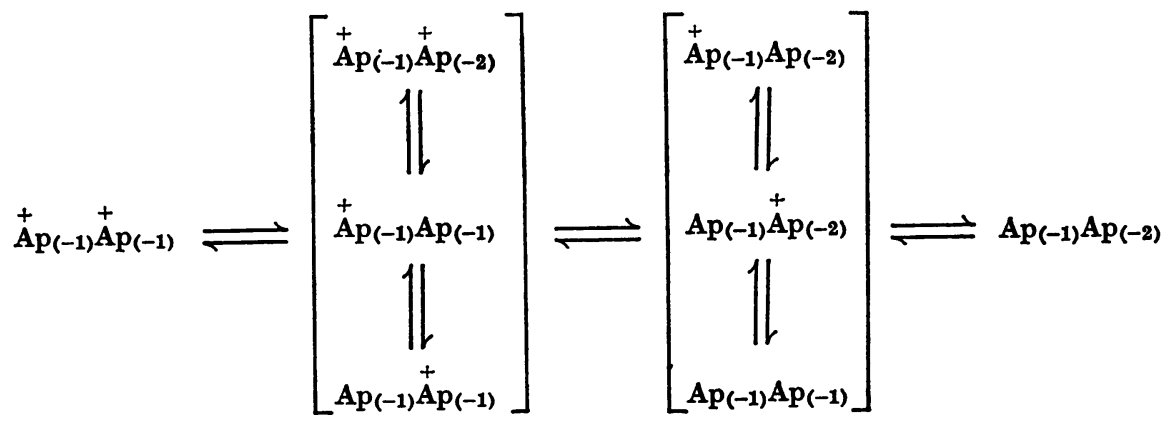

Net charge

Scheme 1.

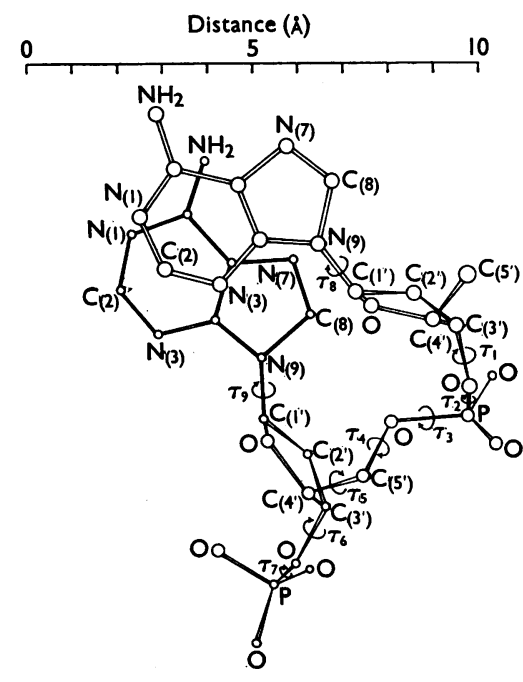

Fig. 4. Probable conformation of $A p A p\left(3^{\prime}\right)$, showing the internal rotations about nine covalent bonds.

the same positions as they would be found in a single strand of the B-form of DNA (Langridge et al. 1960; see also Bush \& Tinoco, 1967), the stacked conformation can be illustrated as in Fig. 4, in which the degrees of freedom available are rotations about the five backbone covalent bonds, $\tau_{1}$ to $\tau_{5}$, the two bonds involved in a $3^{\prime}$-terminal phosphate group, $\tau_{6}$ and $\tau_{7}$, and the two glycosidic linkages, $\tau_{8}$ and $\tau_{9}$. In a single-stranded RNA chain, therefore, the degrees of freedom available per residue are rotations about the six covalent bonds; however, it has been generally accepted that

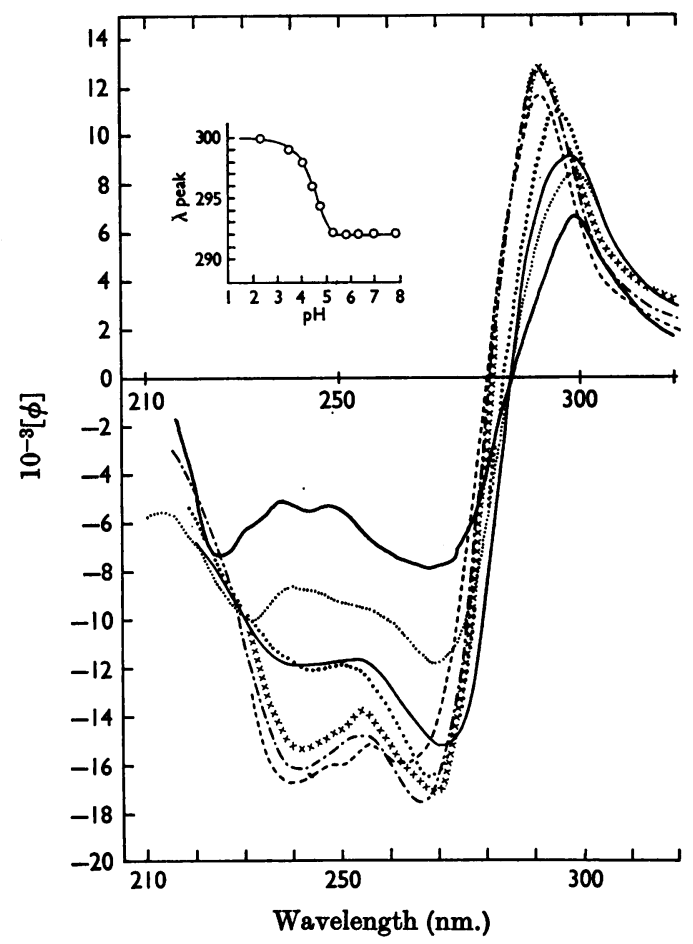

Fig. 5. Spectropolarimetrically followed titration of $\mathrm{CpCp}\left(3^{\prime}\right)$ at $I 0 \cdot 1$ at $20^{\circ}: . . . . . . ., \mathrm{pH} 7 \cdot 84 ;-\cdot \cdot-\cdot-\cdot, \mathrm{pH} 5 \cdot 83$; $\times \times \times \times \times, \mathrm{pH} 5.35 ; \ldots . . ., \mathrm{pH} 4.53 ;-, \mathrm{pH} 4.23$; ......., pH3.53; - $\mathrm{pH} 2.41$. Inset: change of the first Cotton effect peak with $\mathrm{pH}$.

the freedom of the internal rotation about these bonds must be restricted when nearest-neighbour bases are in a parallel position, above one another 


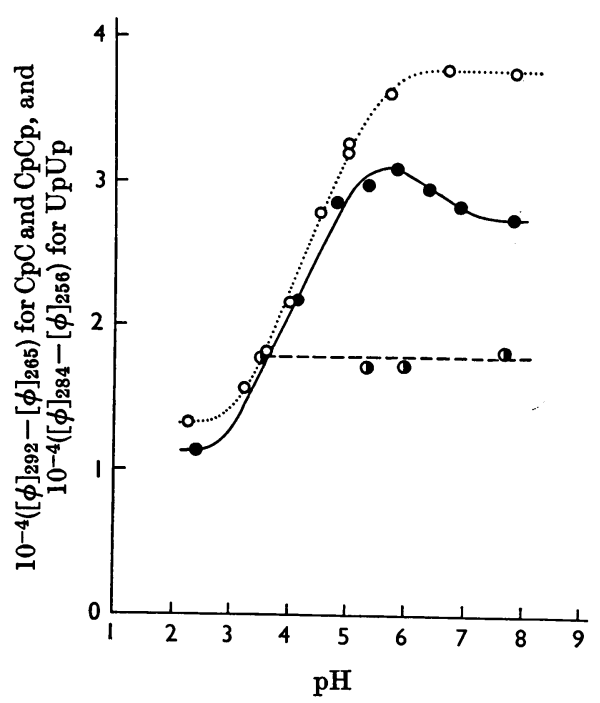

Fig. 6. pH-rotation profiles at $I 0 \cdot 1$ at $20^{\circ}: \bullet, \operatorname{CpCp}\left(3^{\prime}\right)$; O, $\mathrm{CpC} ; \mathrm{O}, \mathrm{UpUp}\left(3^{\prime}\right)$.

with no water in between them (Poland et al. 1966; Bush \& Tinoco, 1967).

On introducing a single- or double-charged 3'-phosphate on ApA, the electrostatic potential should be produced at the site of the backbone phosphate group. Although, as described above, freedom of the internal rotations is restricted, water structure around the molecule is reorganized so as to minimize the overall interaction energy in going from $\operatorname{ApA}$ to $\operatorname{ApAp}\left(3^{\prime}\right)$, and during the titration process of $\operatorname{ApAp}\left(3^{\prime}\right)$. The fine details of the conformational changes, related to the observed ORD changes in $\operatorname{ApAp}\left(3^{\prime}\right), \operatorname{ApAp}\left(3^{\prime}\right) \mathrm{CH}_{3}$ and $\mathrm{ApA}$, and those found for the ionization process :

$$
\begin{array}{r}
\operatorname{Ap}_{(-1)} \mathrm{Ap}_{(-1)}\left(3^{\prime}\right)+\underset{\mathrm{H}_{2} \mathrm{O} \rightleftharpoons}{ } \rightleftharpoons \\
\quad \mathrm{pp}_{(-1)} \mathrm{Ap}_{(-2)}\left(3^{\prime}\right)+\mathrm{H}_{3} \mathrm{O}^{+}
\end{array}
$$

are not understood at the present stage; however, the possible forces involved are disruption of hydrophobic interaction present inside non-polar region allocated between thetwo stacked bases (Hamaguchi \& Geiduschek, 1962). Water molecules tend to line up so as to disperse the charge only at the expense of the non-polar region buried inside becoming more accessible to water molecules. (The observed optical activities in these dimer systems, according to present theories, depend on a number of complex variables. Therefore the effect of the terminal phosphate on the ORD could be explained by possibilities such as a change in the distance between the transition moments of the bases as well as the cross product of the magnetic-moment vectors associated with the transitions.) Similar

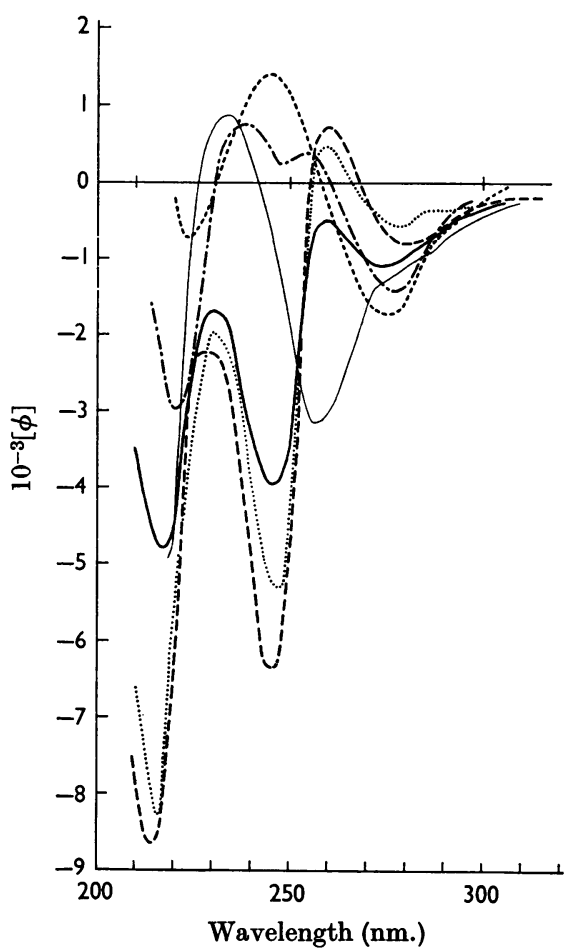

Fig. 7. ORD spectra of $\operatorname{IpIp}\left(3^{\prime}\right)$ and $5^{\prime}-\operatorname{IMP}$ at $25^{\circ}:-$ $\mathrm{IpIp}\left(3^{\prime}\right)$ at $\mathrm{pH} 7 \cdot 0$ and $I 0 \cdot 1$ (adjusted with $\left.\mathrm{KCl}\right) ; \cdots \ldots$. , $\mathrm{IpIp}\left(3^{\prime}\right)$ at $\mathrm{pH} 7 \cdot 0$ and $I \mathbf{1 . 0}$ (adjusted with $\mathrm{KCl}$ ); ----, $\mathrm{IpIp}\left(3^{\prime}\right)$ at $\mathrm{pH} 7.0$ and $I 1.0$ (adjusted with $\mathrm{MgCl}_{2}$ ); -•-•--•, $\mathrm{IpIp}\left(3^{\prime}\right)$ at $\mathrm{pH} 10.08$ and $I 0.1$ (adjusted with $\mathrm{KCl}$ ); $5^{\prime}$-IMP at pH6.9 and $I 0 \cdot 1$ (adjusted with $\mathrm{KCl}$ ); ........, $5^{\prime}$-IMP at $\mathrm{pH} 10 \cdot 82$ and $I 0 \cdot 1$ (adjusted with $\mathrm{KCl}$ ).

effects of $\mathrm{pH}$ were also observed for $\mathrm{CpCp}\left(3^{\prime}\right)$, and the results of ORD titrations of $\mathrm{CpCp}\left(3^{\prime}\right)$ and $\mathrm{CpC}$ are shown in Figs. 5 and 6. The ORD titration of $\mathrm{CpCp}\left(3^{\prime}\right)$ exhibits a maximum of the rotation measured as $[\phi]_{292}-[\phi]_{265}$ at $\mathrm{pH} 5 \cdot 7$. The frequency shifts of the peak of the first Cotton effect permit us to estimate an apparent basic $\mathrm{p} K_{a}$ value of approx. 4.4 for $\mathrm{CpCp}\left(3^{\prime}\right)$. Consequently, we could not observe the ORD spectrum characteristic of $\mathrm{Cp}_{(-1)} \mathrm{Cp}_{(-1)}\left(3^{\prime}\right)$, but the rotational contribution due to this ionic species can be estimated from the $\mathrm{pH}$-rotation profile in Fig. 6 with the aid of the Henderson equation, which gives a value of $3.31 \times 10^{4}$ degrees/residue as $[\phi]_{292}-[\phi]_{265}$ for $\mathrm{Cp}_{(-1)} \mathrm{Cp}(-1)\left(3^{\prime}\right)$.

The ORD and hypochromicity measurements of UpU showed that the stacked conformation is less favoured at room temperature; uracil is believed to be the most hydrated base among 16 possible dinucleoside phosphates (Warshaw \& Tinoco, 1965; Tinoco, Davis \& Jaskunas, 1968). No change 


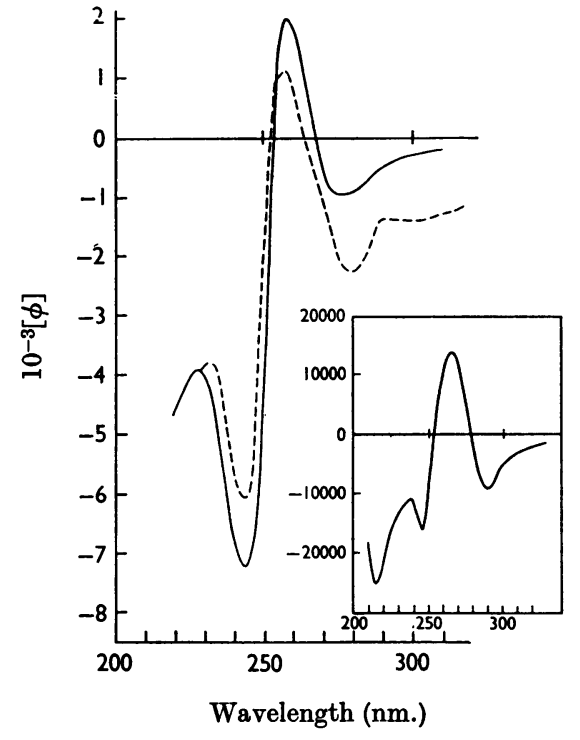

Fig. 8. Calculated and experimental ORD curves of polyI at neutral $\mathrm{pH}$ in low salt concentration: - $\longrightarrow$, calculated from the data based on $\operatorname{IpIp}\left(3^{\prime}\right)$ and $5^{\prime}$-IMP at $25^{\circ}$ by using the equation:

$$
[\phi]_{\text {polyI }}=2[\phi]_{\mathrm{IpIp}}-[\phi]_{5^{\prime}} \text {.IMP }
$$

........, experimental results obtained by Sarkar \& Yang (1965), in $0.1 \mathrm{M}-\mathrm{NaCl}$ and $0.01 \mathrm{M}$-glycylglycine at $27^{\circ}$. Inset: experimental ORD of polyI at high salt concentration (1 M-NaCl+0.01 $\mathrm{m}-\mathrm{EDTA}$ ) at $\mathrm{pH} 7.0$ at $27^{\circ}$ (Sarkar \& Yang, 1965).

found for $\mathrm{UpUp}\left(3^{\prime}\right)$ at $20^{\circ}$ during the ORD titration at the $\mathrm{pH}$ range of the acidic $\mathrm{p} K_{a}$ of the secondary phosphate is thus consistent with the previously observed behaviour of UpU and polyU.

The effect of $\mathrm{pH}$ on the ORD curves of adenylate and cytidylate dimers at the range of the basic $\mathrm{p} K_{a}$ values of adenine and cytosine has been commonly observed not only for dinucleoside phosphates but also for other oligo- and poly-nucleotides. The ORD of these nucleotides at $\mathrm{pH}$ below $\mathrm{p} K_{a}-2$ are almost identical with the sum of the molecular rotations of the component monomers in their protonated forms. This is easily understood if one considers the charge repulsion by which the two protonated bases of a dinucleotide move freely through water constrained only by covalent linkage between them (Davis \& Tinoco, 1968).

ORD spectrum of di-inosinic acid, $I p I p\left(3^{\prime}\right)$. Although conformational changes of polyI were studied by the ORD technique (Sarkar \& Yang, 1965), no optical properties have been reported for IpI or IpIp to date. The objective of the present study is to obtain experimental information about

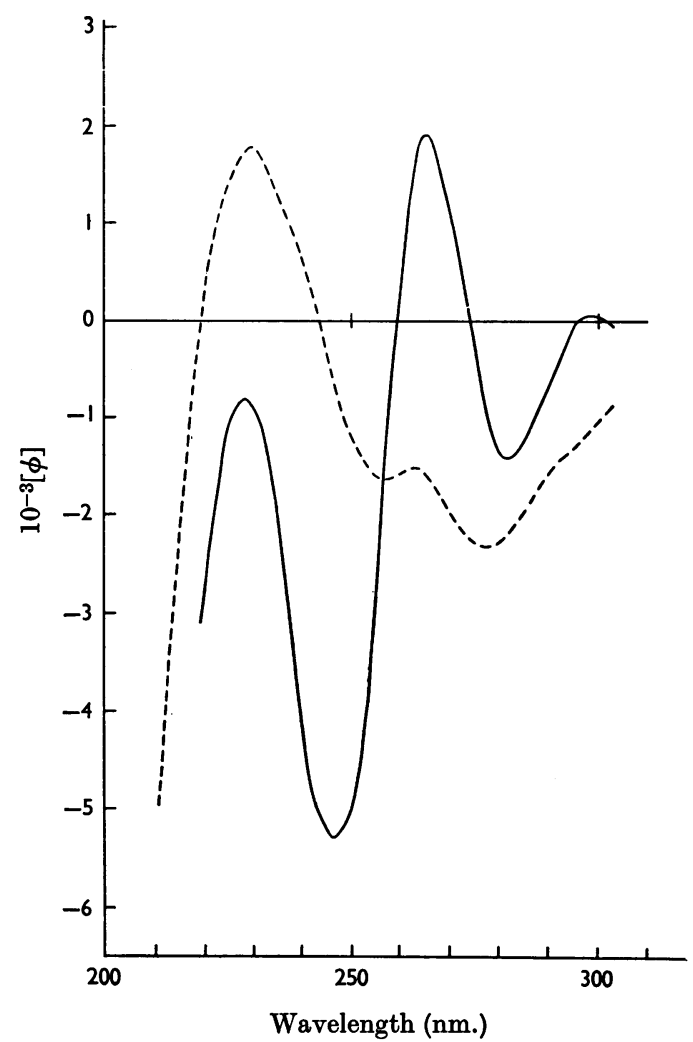

Fig. 9. ORD spectra of $\operatorname{GpGp}\left(3^{\prime}\right)$ (-) and $5^{\prime}$-GMP $(-\ldots . .$.$) at \mathrm{pH} 7 \cdot 0$ and $I 0 \cdot 1$ at $25^{\circ}$.

the optical properties of IpIp in aqueous solutions and to see whether or not the observed ORD of polyI at a low ionic strength can be accounted by nearest-neighbour calculations based on the data for IpIp and $5^{\prime}$-IMP. The ORD data for $\operatorname{IpIp}\left(3^{\prime}\right)$, measured as a function of $\mathrm{pH}$ and electrolyte concentration, are shown in Fig. 7 together with the data for $5^{\prime}$-IMP. The ORD spectrum of $\operatorname{IpIp}\left(3^{\prime}\right)$ at $25^{\circ}$ at $\mathrm{pH} 7$ and $I 0 \cdot 1$ is not identical with that of the monomer, and the u.v. spectrum is also differentiated by the hypochromicity of $6.0 \%$ at $260 \mathrm{~nm}$. The shape of the ORD spectrum of IpIp remains qualitatively the same on varying the ionic strength of the solvent, but the magnitude defined as $[\phi]_{260}-[\phi]_{246}$ increases as much as $68 \%$ on going from $I 0.1$ to $I 1.0$ by the addition of potassium chloride, and more than $100 \%$ change was observed when magnesium chloride was added to adjust ionic strength to $1 \cdot 0$. The extent to which the magnitude of the ORD of IpIp changed with salt concentration is far larger than the corresponding change for $\operatorname{ApAp}\left(3^{\prime}\right)$, indicating that the selfassociation may be considered at a dinucleotide 


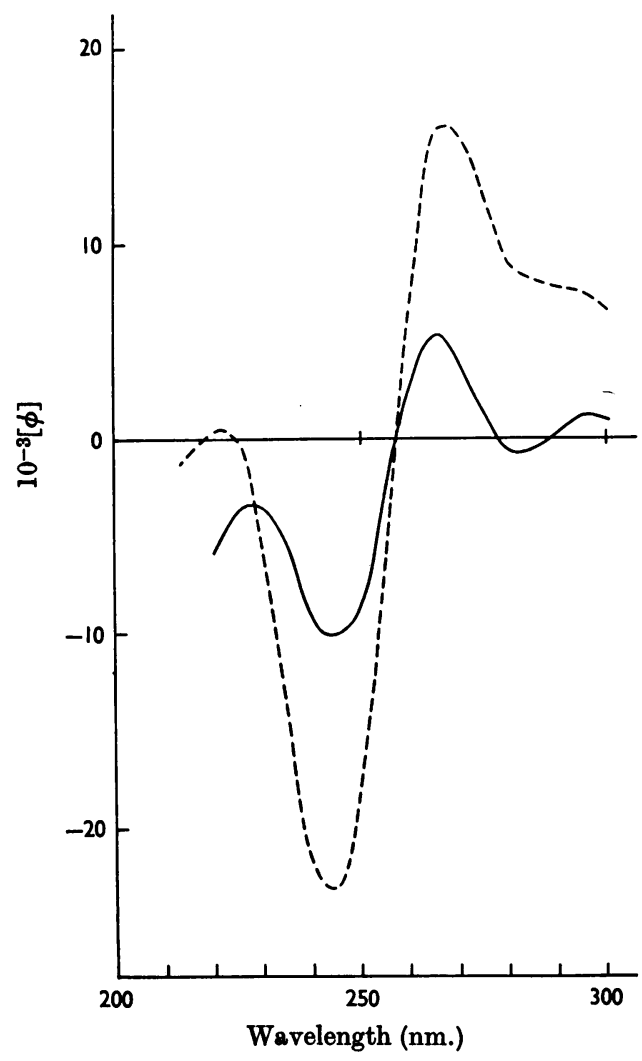

Fig. 10. ORD spectra of polyG at pH 7: - , calculated from data in Fig. 9 by using the equation:

$$
[\phi]_{\mathrm{polyg}}=2[\phi]_{\mathrm{GpGp}}-[\phi]_{5^{\prime}-\mathrm{GMP}}
$$

........, experimental results obtained by Ulbricht, Swan \& Michelson (1966) at $I 0 \cdot 15$ at room temperature.

level as a possible interpretation of this anomalous salt effect (cf. Sarkar \& Yang, 1965).

A fair agreement between the experimental ORD curve of polyI and calculated results based on the ORD data for $\operatorname{IpIp}\left(3^{\prime}\right)$ and $5^{\prime}$-IMP at $I 0 \cdot 1$ suggests that the average conformation of neighbouring bases in polyI is reasonably well approximated by that of IpIp (cf. Cantor et al. 1966; Inoue, Masuda \& Aoyagi, 1968).

$O R D$ spectrum of diguanylic acid, $G p G p\left(3^{\prime}\right)$. Compilation of the experimental data for 15 dinucleoside phosphates necessary for nearestneighbour ORD calculations was made by Warshaw \& Tinoco $(1965,1966)$. However, no direct experimental results were available for guanylate dimer, and so we prepared GpGp( $\left.3^{\prime}\right)$ and measured its ORD. The results are reproduced in Fig. 9. The shape of the ORD spectrum is similar to that of IpIp, which is distinguished from those of the other dinucleotides by having two troughs and one peak between 240 and $300 \mathrm{~nm}$. As is expected from the known highly aggregative nature of polyG (Pochon \& Michelson, 1965), large discrepancies in magnitude between calculated and experimental ORD were observed. These discrepancies indicate that a regular array of GpGp is not a sufficient description of the structure of polyG, and even at a low salt concentration polyG is present in a more organized structure.

This paper is part 8 of the series ' Oligonucleotide Studies' (part 7: Irie, Egami \& Inoue, 1969).

\section{REFERENCES}

Aoyagi, S. \& Inoue, Y. (1968a). J. biol. Chem. 248, 514.

Aoyagi, S. \& Inoue, Y. (1968b). J. Biochem., Tokyo, 64, 603.

Brahms, J., Michelson, A. M. \& Van Holde, K. E. (1966). J. molec. Biol. 15, 467.

Bush, C. A. \& Tinoco, I., jun. (1967). J. molec. Biol. 23, 601.

Cantor, C. R., Jaskunas, S. R. \& Tinoco, I., jun. (1966). J. molec. Biol. $20,29$.

Cantor, C. R. \& Tinoco, I., jun. (1965). J. molec. Biol. 13, 65.

Cantor, C. R. \& Tinoco, I., jun. (1967). Biopolymers, 5, 821.

Davis, R. C. \& Tinoco, I., jun. (1968). Biopolymers, 6, 223.

Fasman, G. D., Lindblow, C. \& Grossman, L. (1964). Biochemistry, 8, 1015.

Haines, J. A., Reese, C. B. \& Todd (Lord) (1964). J. chem. Soc. p. 1406.

Hamaguchi, K. \& Geiduschek, E. P. (1962). J. Amer. chem. Soc. 84, 1329.

Holcomb, D. N. \& Tinoco, I., jun. (1965). Biopolymers, 8, 121.

Inoue, Y. \& Aoyagi, S. (1967). Biochem. biophys. Res. Commun. 28, 973.

Inoue, Y. \& Aoyagi, S. (1969). J. physiol. Chem. Phys. (in the Press).

Inoue, Y., Aoyagi, S. \& Nakanishi, K. (1967). J. Amer. chem. Soc. 89, 5701.

Inoue, Y., Masuda, M. \& Aoyagi, S. (1968). Biochem. biophys. Res. Commun. 81, 577.

Irie, S., Egami, F. \& Inoue, Y. (1969). J. Amer. chem. Soc. 91, 1582.

Jaskunas, S. R., Cantor, C. R. \& Tinoco, I., jun. (1968). Biochemistry, 7, 3164.

Langridge, R., Marvin, D. A., Seeds, W. E., Wilson, H. R., Hooper, C. W., Wilkins, M. H. F. \& Hamilton, L. D. (1960). J. molec. Biol. 2, 38.

Leng, M. \& Felsenfeld, G. (1966). J. molec. Biol. 15, 455.

Lipsett, M. N. (1964). J. biol. Chem. 239, 1250.

Nirenberg, M. \& Leder, P. (1964). Science, 145, 1399.

Pochon, F. \& Michelson, A. M. (1965). Proc. nat. Acad. Sci., Wash., 53, 1425.

Poland, D., Vournakis, J. N. \& Scheraga, H. A. (1966). Biopolymers, 4, 223.

Sarkar, P. K. \& Yang, J. T. (1965). Biochemistry, 4, 1238.

Satoh, K. \& Inoue, Y. (1969). Biochem. $J$. (in the Press).

Schweizer, M. P., Broom, A. D., Ts'o, P. O. P. \& Hollis, D. P. (1968). J. Amer. chem. Soc. 90, 1042.

Simpkins, H. \& Richards, E. G. (1967a). J. molec. Biol. 29, 349. 
Simpkins, H. \& Richards, E. G. (1967b). Biochemistry, 6, 2513.

Tinoco, I., jun. Davis, R. C. \& Jaskunas, S. R. (1968). In Molecular Associations in Biology, p. 77. Ed. by Pullman, B. New York and London: Academic Press Inc.

Uchida, T. \& Egami, F. (1965). J. Biochem., Tokyo, 57, 743.

Ulbricht, T. L. V., Swan, R. S. \& Michelson, A. M. (1966). Chem. Commun. p. 63.

Van Holde, K. E., Brahms, J. \& Michelson, A. M. (1965). J. molec. Biol. 12, 726.
Vournakis, J. N., Scheraga, H. A., Rushizky, G. W. \& Sober, H. A. (1966). Biopolymers, 4, 33.

Warshaw, M. M., Bush, C. A. \& Tinoco, I., jun. (1965). Biochem. biophys. Res. Commun. 18, 633.

Warshaw, M. M. \& Tinoco, I., jun. (1965). J. molec. Biol. 13, 54.

Warshaw, M. M. \& Tinoco, I., jun. (1966). J. molec. Biol. 20, 29.

Yang, J. T., Samejima, T. \& Sarkar, P. K. (1966). Biopolymers, 4, 623. 